\title{
Clinical use of venoarterial extracorporeal membrane oxygenation
}

\author{
George WY Ng *, Henry J Yuen, KC Sin, Anne KH Leung, KW Au Yeung, KY Lai
}

This article was published on 5 May 2017 at www.hkmj.org.

\begin{abstract}
A B S T R A C T
With advances in mechanical circulation, venoarterial extracorporeal membrane oxygenation has become an established technique to provide cardiopulmonary support for patients with cardiovascular collapse. This article reviews the physiological principles of such extracorporeal $K$ technique and its interaction with the native heart. Practical aspects including equipment, patient selection, and common complications with their prevention and specific management are summarised. The strategy for weaning from venoarterial extracorporeal membrane oxygenation is also discussed.
\end{abstract}

\section{Hong Kong Med J 2017;23:282-90} DOI: $10.12809 / \mathrm{hkmj} 166096$

GWY Ng *, FCICM, FHKAM (Medicine)

HJ Yuen, FHKCA(Intensive Care), FHKAM (Anaesthesiology)

KC Sin, FHKCP, FHKAM (Medicine)

AKH Leung, FCICM, FHKAM (Anaesthesiology)

KW Au Yeung, FCICM, FHKAM (Anaesthesiology)

KY Lai, FRCP (Edin), FHKAM (Medicine)

Department of Intensive Care, Queen Elizabeth Hospital, Jordan, Hong Kong

* Corresponding author: georgeng77@yahoo.com

\section{Introduction}

Venoarterial extracorporeal membrane oxygenation (VA-ECMO) is an extracorporeal life support system that can temporarily provide support to the body circulation while the pumping function of the heart is absent or very weak. It is used in different scenarios of severe cardiac failure to support the patient and serves as a bridge to recovery, to implantation of a ventricular assist device, or to transplantation.

\section{Types of extracorporeal membrane oxygenation circuits}

The basic ECMO circuit comprises a non-pulsatile pump for blood propulsion, and a membrane oxygenator for gas exchange. In general, an ECMO circuit can have two configurations: venovenous (VV) and venoarterial (VA). While VV-ECMO provides only pulmonary support, VA-ECMO can provide both pulmonary and cardiac support. Of note, VA-ECMO can be categorised further into central VA and peripheral VA.

\section{Peripheral}

The VA-ECMO technique can provide both respiratory and cardiac support. The circuit is connected in parallel to the heart and lungs. In peripheral VA-ECMO, the access cannula is usually placed in either the right internal jugular vein or the femoral vein. Deoxygenated blood is extracted from the right heart circulation by a motor pump that then drives the blood through an oxygenator.
Oxygen diffuses across the oxygenator membrane into the blood that is returned to the arterial system via the return cannula placed either at the femoral or axillary artery (Fig 1a).

\section{Central}

In central VA-ECMO, the access cannula is usually placed in the right atrium. This requires surgical placement with an open sternotomy (Fig 1b). The oxygenated blood returns to the arterial system via the return cannula placed in the ascending aorta.

\section{Clinical indications and contra- indications for venoarterial extracorporeal membrane oxygenation}

According to the Extracorporeal Life Support Organization (ELSO) Registry, $41 \%$ of all patients who underwent VA-ECMO survived to discharge or transfer. ${ }^{1}$ On the contrary, the intra-aortic balloon pump (IABP) was shown to have no survival benefit over conventional medical treatment alone., ${ }^{2,3}$ Therefore, VA-ECMO has emerged as the first-line treatment to provide rapid support to patients with cardiogenic shock, defined as a state of end-organ hypoperfusion due to cardiac failure. Nonetheless, ECMO therapy is not an ultimate treatment. It only helps to sustain life for bridging to a definitive plan. Careful selection of suitable candidates for VA-ECMO is vital for a favourable outcome. Table 1 illustrates the common indications for and contraindications to VA-ECMO., 


\section{Physiology of the artificial heart}

\section{Support to the native heart}

Unlike cardiopulmonary bypass, VA-ECMO provides only approximately $80 \%$ of the predicted resting cardiac output in the ideal setting. The rest of the perfusion is still provided by the native heart. ${ }^{6}$ Of note, VA-ECMO allows the heart to rest by decreasing venous return and subsequent volume work, wall tension, and oxygen consumption of the heart. ${ }^{6}$ In addition, animal studies have shown that the decrease in preload decreases left ventricular end-diastolic volume and pressure, thus promoting a better coronary perfusion pressure due to a greater pressure gradient (coronary perfusion pressure = aortic diastolic pressure - left ventricular enddiastolic pressure). ${ }^{7,8}$ The return of oxygenated blood from the ECMO circuit to the arterial system, however, may negatively affect the left ventricle (LV) by increasing afterload and the pressure work of the myocardium. ${ }^{9}$ The overall effect of the decrease in volume work and the increase in pressure work depends on the degree of ECMO support as well as the native myocardial function and its response to these triggers.

After commencing peripheral VA-ECMO support, there is initially a decrease in cardiac performance due to an increase in LV afterload. The cardiac performance can usually return to baseline by 72 hours. ${ }^{10}$ Right and left ventricular stroke

\section{靜脈一動脈體外膜氧合的臨床使用}

吳榮耀、袁愷寅、洗佳卓、梁結雄、歐陽健華、黎鏡堯

隨着機械通氣治療技術的進步, 靜脈一動脈體外膜氧合（VAECMO ）經已成為一種成熟的技術, 為心臟衰竭患者提供心肺功能 支持。本文回顧這種體外技術的生理學原理，以及它與患者自身心臟 的相互作用；並概述患者篩選、併發症預防和針對性管理，以及討論 VA-ECMO撤離的策略。

volumes are almost identical at baseline but vary inversely with increasing ECMO pump flow rates. The mean arterial pressure (MAP) is directly related to the total aortic flow, which is the summation of the native cardiac output and the ECMO pump flow. The MAP should be kept above $60 \mathrm{~mm} \mathrm{Hg}$ for adequate organ perfusion:

$\mathrm{MAP}=($ native $\mathrm{CO}+$ pump flow $) \times \mathrm{SVR}$

(where $\mathrm{CO}=$ cardiac output; $\mathrm{SVR}=$ systemic vascular resistance)

The blood flow created by ECMO is nonpulsatile. The patient with poor heart contractility will have a narrow pulse contour and a small pulse pressure. Absence of pulsatility in the arterial waveform means that there is no blood being ejected from the LV. At this point the aortic valve does not open due to poor heart contractility, and total bypass

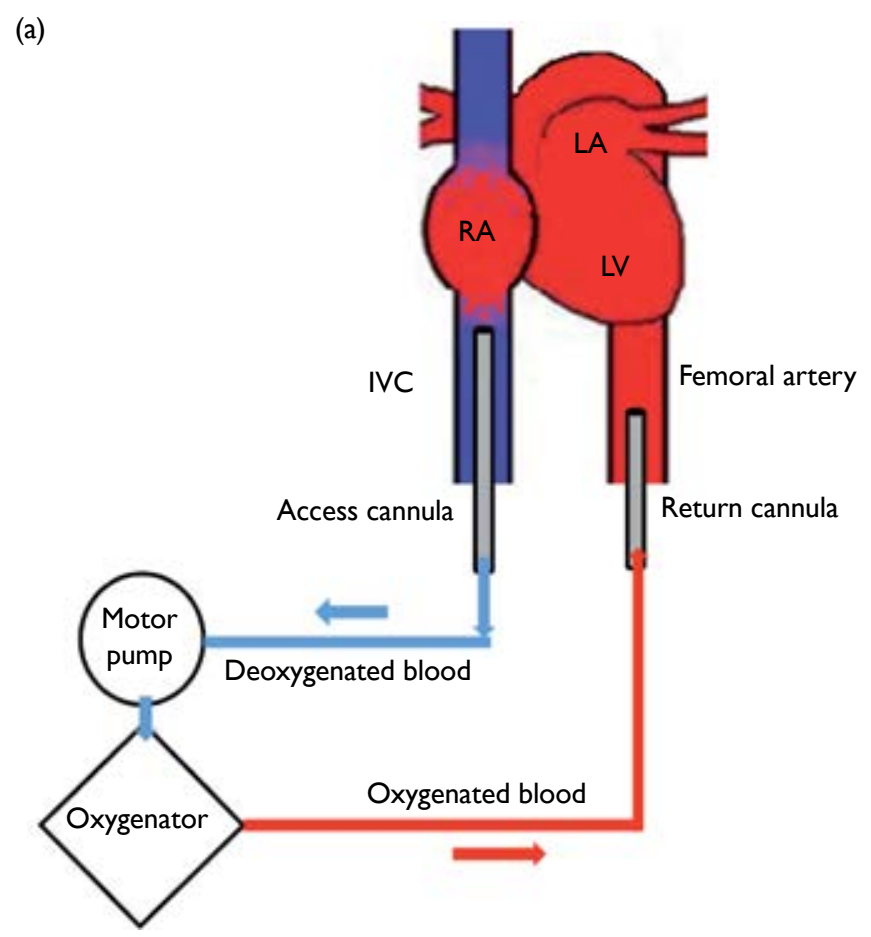

(b)

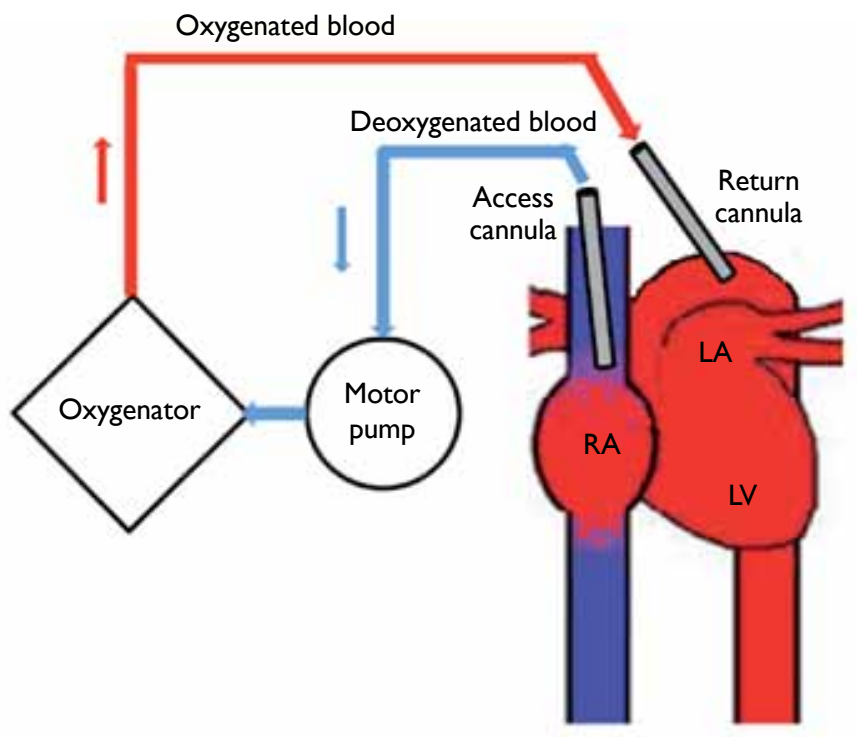

FIG I. Two different configurations of venoarterial extracorporeal membrane oxygenation (VA-ECMO)

(a) Peripheral and (b) centralVA-ECMO

Abbreviations: IVC = inferior vena cava; $L A=$ left atrium; $L V=$ left ventricle; $R A=$ right atrium 
TABLE I. Common indications for and contra-indications to VA-ECMO

\begin{tabular}{|c|c|}
\hline Indication & Contra-indication \\
\hline $\begin{array}{l}\text { In patients with cardiogenic shock: } \\
\text { - } \text { Acute coronary syndrome } \\
\text { - } \text { Pyocarditis } \\
\text { - } \text { Cardiac arrhythmia refractory to other measures } \\
\text { - } \text { Drug overdose/toxicity with profound cardiac depression } \\
\text { - } \text { Acute anaphylaxis } \\
\text { - Pulmonary embolism } \\
\text { - Sepsis with profound cardiac depression } \\
\text { - Post-cardiotomy shock: inability to wean from cardiopulmonary bypass after } \\
\text { As a bridge to a more definitive treatment: } \\
\text { - Post-heart transplant: primary graft failure after heart or heart-lung transplantation } \\
\text { - Chronic cardiomyopathy: } \\
\text { o As a bridge to longer-term VAD support or } \\
\text { - } \text { Periprocedural support for high-risk percutaneous cardiac interventions } \\
\text { - Bridge to heart transplant }\end{array}$ & $\begin{array}{l}\text { Absolute: } \\
\text { - Unrecoverable heart and not a candidate for transplant } \\
\text { - } \text { or VAD support } \\
\text { - Known severe brain injury } \\
\text { - Unwitnessed cardiac arrest } \\
\text { - Prolonged CPR without adequate tissue perfusion } \\
\text { - Unrepaired aortic dissection } \\
\text { - Severe aortic regurgitation } \\
\text { - Severe chronic organ dysfunction (emphysema, } \\
\text { - } \text { cirrhosis, renal failure) } \\
\text { Peripheral VA-ECMO is contra-indicated in severe } \\
\text { Relative: } \\
\text { - Contra-indication for anticoagulation, advanced age, } \\
\text { and obesity }\end{array}$ \\
\hline
\end{tabular}

Abbreviations: CPR = cardiopulmonary resuscitation; VAD = ventricular assist device; VA-ECMO = venoarterial extracorporeal membrane oxygenation

occurs (ECMO circuit takes over 100\% of the cardiac output).

\section{Oxygenation}

With the same blood flow and extracorporeal circuit setting, VA-ECMO may theoretically provide better lung support than VV-ECMO. First, the artificially oxygenated blood returns directly to the arterial systemic circulation to perfuse end-organs. Second, in the presence of hypoxia, the pulmonary arteries constrict so that blood is directed to the alveoli with higher oxygen content. The extracorporeal circuit of VV-ECMO is connected in series with the native lungs. When blood with a high oxygen saturation from the return cannula reaches the pulmonary arteries, the shunt fraction of the native lung will increase due to the loss of hypoxic pulmonary vasoconstriction. In VA-ECMO, the extracorporeal circuit is in parallel with the native lungs. The return of oxygenated blood bypasses the venous and pulmonary circulation so there is no loss of oxygenation via the native lungs. ${ }^{11}$

\section{Combined use of an intra-aortic balloon pump and extracorporeal membrane oxygenation}

Peripheral VA-ECMO increases the afterload of the $\mathrm{LV}$ as it directs blood into the descending aorta in a retrograde direction. Intra-aortic balloon pump deflates in systole and inflates in diastole and helps reduce afterload and improve coronary perfusion, respectively. An IABP is sometimes used concomitantly with VA-ECMO, especially for those patients who are already on IABP but still have refractory shock. It is believed that the concomitant use of IABP can facilitate aortic valve opening and achieve better LV decompression, improve aortic diastolic pressure and thus coronary perfusion. ${ }^{12}$ A recent meta-analysis, however, found that the concomitant use of IABP and ECMO in adult patients with cardiogenic shock and cardiac arrest offered no survival benefit. $2,3,13,14$ Special attention should be paid to the arterial waveform when using IABP with VA-ECMO. The pressure waveform generated by the IABP and the arterial pulsation generated by the native heart may have similar morphology. We recommend examining the native arterial pulsation with the IABP set to 2:1 assist ratio, and checking for aortic valve opening by echocardiography with the IABP on standby (Fig 2).

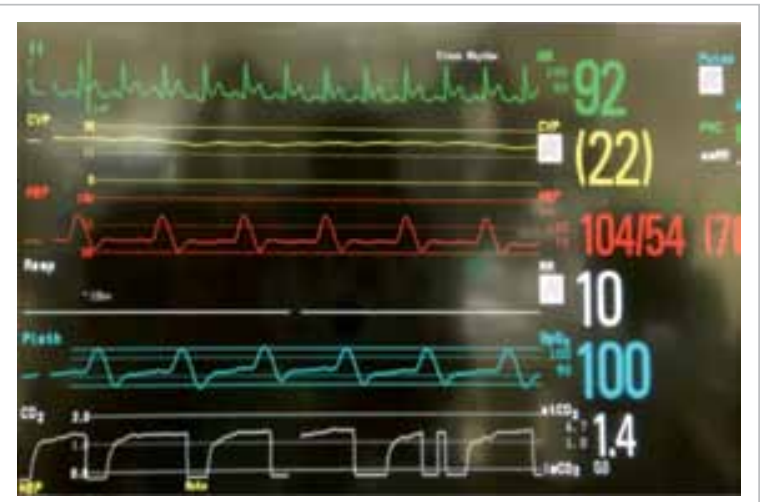

FIG 2. Relationship of electrocardiogram and arterial waveform in a patient with concomitant use of intra-aortic balloon pump (IABP) and venoarterial extracorporeal membrane oxygenation (VA-ECMO)

The patient was concomitantly supported by IABP (2: I ratio) and VA-ECMO.The electrical cardiac rhythm and arterial pulsation was in a $2:$ I ratio. The arterial pulsation was generated by the IABP only. If IABP is switched off, only the mean arterial pressure is present and there is no pulse pressure seen 


\section{Procedure}

\section{Cannulation}

In peripheral VA-ECMO, the access cannula is normally placed in the common femoral vein or the right internal jugular vein. The return cannula is usually placed in the common femoral artery with the tip located in the iliac artery or abdominal aorta. The cannulation procedure is accomplished at the bedside via a Seldinger technique and serial dilatation under ultrasound or fluoroscopic guidance. Ultrasound is commonly used for cannulation in the intensive care unit setting. The femoral artery is round in shape and pulsatile, has a thicker wall, is less easily compressed, and is lateral to the femoral vein. In small patients, ultrasound estimation of the vessel calibre is particularly useful to select an appropriately sized cannula and predict the need for distal limb perfusion. The guidewire of the return cannula should preferably be visualised by transoesophageal echocardiography or fluoroscopy to confirm placement in the lumen of the aorta before dilatation.

In central VA-ECMO, cannulation is done in the operating theatre by the cardiothoracic surgical team. The access cannula is placed in the right heart circulation (superior vena cava or right atrium) and the return cannula in the ascending aorta through an open sternum. This is usually performed when the patient fails to wean from cardiopulmonary bypass after open heart surgery, as direct access is already available.

\section{Priming of circuit}

The circuit, pump head, and oxygenator should be primed with $0.9 \%$ normal saline before use so that air inside the circuit is eliminated. The priming procedure is done passively by gravity drainage from the priming bag followed by active priming by the ECMO machine.

\section{Reperfusion cannula}

The femoral artery is commonly used for cannulation in peripheral VA-ECMO due to its ease of access. As the return cannula is placed in a retrograde direction in the femoral artery, perfusion of the ipsilateral lower limb may be compromised as the direction of blood flow from the return cannula is opposite to that from the native heart. The risk of distal limb ischaemia is even higher if large-size cannulas are used. Successful distal limb perfusion in VA-ECMO has been reported using various approaches, including antegrade cannulation of the superficial femoral artery, and retrograde cannulation of the dorsalis pedis or posterior tibial artery. ${ }^{15-17}$ Antegrade percutaneous cannulation of the superficial femoral artery is the most commonly used technique in our locality. The reperfusion cannula should be placed using the Seldinger technique under fluoroscopic or ultrasound guidance. If ultrasound is used, in-plane visualisation is helpful to differentiate the superficial femoral artery from the deep femoral artery, and to guide the angle and depth of the puncture needle (Fig 3a). The proximal end of the reperfusion cannula is connected to the return cannula of the ECMO circuit so that oxygenated blood can directly perfuse the distal part of the lower limb (Fig 3b). Surgical exposure for vascular access is an alternative in difficult cases. A blood flow of $100-150 \mathrm{~mL} / \mathrm{min}$ in the superficial femoral artery is usually sufficient to perfuse the leg. ${ }^{15,17}$ An additional flowmeter can be used to monitor the blood flow of this limb of the circuit.

\section{Possible complications related to venoarterial extracorporeal membrane oxygenation}

The outcome of patients treated with VA-ECMO is dependent on two factors: careful selection of patients and avoidance of ECMO-related complications. Improved understanding and

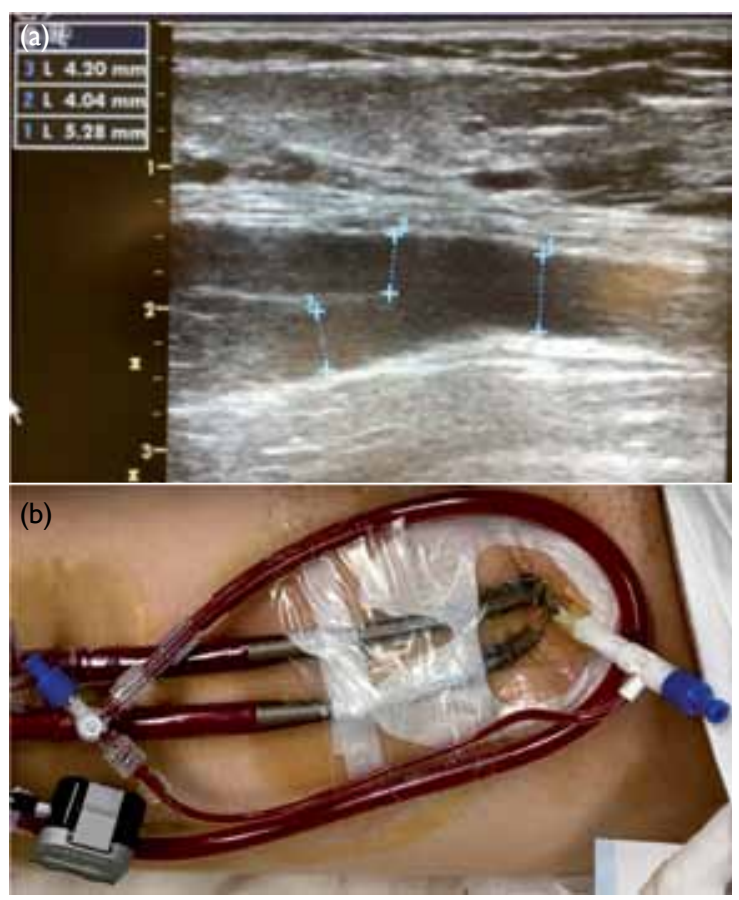

FIG 3. Reperfusion cannula to the venoarterial extracorporeal membrane oxygenation (VA-ECMO) (a) Ultrasound is used to assess size of femoral artery and assist insertion of reperfusion cannula. In-plane visualisation method is used during reperfusion cannula insertion. The reperfusion cannula should be placed inside the superficial femoral artery. (b) The reperfusion cannula and return cannula in the femoral artery have different directions of blood flow. The proximal end of the reperfusion cannula is connected to the return cannula of the ECMO circuit so that oxygenated blood can directly perfuse the distal part of the lower limb 
TABLE 2. Common complications of VA-ECMO

\begin{tabular}{|c|c|}
\hline Common complication & Cause \\
\hline \multicolumn{2}{|l|}{ Medical complications (related to the sick native heart) } \\
\hline $\begin{array}{l}\text { Arrhythmias } \\
\text { Hypotension } \\
\text { Acute pulmonary oedema }\end{array}$ & $\begin{array}{l}\text { Acute myocardial infarction, electrolyte disturbances } \\
\text { Worsening of cardiogenic shock } \\
\text { Fluid overload, acute heart failure }\end{array}$ \\
\hline \multicolumn{2}{|l|}{ ECMO-related complications } \\
\hline $\begin{array}{l}\text { Internal bleeding (eg Gl tract, cerebral) } \\
\text { Acute pulmonary oedema } \\
\text { Thrombus formation inside left atrium and ventricle } \\
\text { Differential hypoxia }\end{array}$ & $\begin{array}{l}\text { Over-anticoagulation } \\
\text { Aortic valve does not open due to excessive ECMO blood flow } \\
\text { Under-anticoagulation; stagnant blood inside LV } \\
\text { Co-existing poor respiratory function, eg pneumonia }\end{array}$ \\
\hline \multicolumn{2}{|l|}{ Mechanical: cannula/circuit-related } \\
\hline $\begin{array}{l}\text { Vascular injury due to cannulation } \\
\text { Cannula insertion site hematoma } \\
\text { Haemolysis } \\
\text { Gas embolism } \\
\text { Limb ischaemia }\end{array}$ & $\begin{array}{l}\text { Trauma to vessel wall / difficult cannulation } \\
\text { Trauma to vessel wall / difficult cannulation } \\
\text { High pump speed, clots in oxygenator } \\
\text { Cracked three-way tap, dislodgment of cannula, disconnection of circuit } \\
\text { Peripheral vascular disease, no distal reperfusion cannula }\end{array}$ \\
\hline
\end{tabular}

Abbreviations: $\mathrm{Gl}=$ gastrointestinal; $\mathrm{LV}=$ left ventricle; $\mathrm{VA}-\mathrm{ECMO}=$ venoarterial extracorporeal membrane oxygenation

heightened awareness of known complications are good preventive measures. Early detection and timely treatment may prevent or mitigate harm to patients due to complications. Table 2 shows the common complications related to VA-ECMO.

\section{General complications}

\section{Bleeding}

Bleeding is one of the most frequent complications and may lead to catastrophic events. Bleeding can occur at the sternotomy wound in central VA$\mathrm{ECMO}$, the cannulation sites in peripheral VAECMO, and gastrointestinal, intra-abdominal, intrathoracic, or intracranial areas. Risk factors for severe bleeding include central VA-ECMO, use of dua antiplatelet agents, platelet dysfunction, and over anticoagulation.

\section{Neurological complications}

According to the ELSO Registry, approximately $15 \%$ of patients who received VA-ECMO developed neurological complications. Among the 4522 adult patients supported with VA-ECMO from 1992 to 2013, 358 (7.9\%) had brain death, 161 (3.6\%) had a cerebral infarction, 83 (1.8\%) developed seizures, and $80(1.8 \%)$ were found to have cerebral haemorrhage. ${ }^{18}$ Those who developed neurological complications had a significantly higher hospital mortality rate than those who did not. Neurological complications were more frequently observed in patients who required cardiopulmonary resuscitation before receiving VA-ECMO. Age, ${ }^{19}$ pre-ECMO cardiac arrest, use of inotropes while on ECMO, and postECMO hypoglycaemia were associated with the development of neurological complications. ${ }^{18}$

Cerebral hypoxia and hypoperfusion after cardiac arrest, post-resuscitation reperfusion injury, coagulopathy, and thromboembolism are usually the underlying causes of neurological complications. Presence of intracranial haemorrhage in patients supported with VA-ECMO had a mortality rate of higher than $90 \%$. Kasirajan et $\mathrm{al}^{20}$ reported that female gender and thrombocytopaenia, especially with platelet counts of $<50000$ cells $/ \mathrm{mm}^{3}$, were predictors of intracranial haemorrhage.

\section{Haemolysis}

The new generation of centrifugal pumps is safer and causes less haemolysis related to blood stagnation, heating, and thrombosis. They are, however, still associated with some degree of haemolysis. The haemolysis is usually caused by cavitation rather than mechanical shearing or squeezing of red cells. When the pump speed is more than 3000 revolutions per minute, the negative pressure generated within the pump head can exceed $-700 \mathrm{~mm} \mathrm{Hg}$ and cavitation may occur. ${ }^{21}$ Plasma-free haemoglobin level will be elevated when haemolysis is significant. The increase in plasma-free haemoglobin is a risk factor for acute kidney injury during ECMO. ${ }^{22}$

\section{Complications specific to venoarterial extracorporeal membrane oxygenation}

\section{Thrombus formation}

In patients with severe LV dysfunction, stasis of blood can occur at sites of stagnant flow. The retrograde flow of blood from peripheral VA-ECMO can oppose the opening of the aortic valve if LV contractility is very poor. Lack of cardiac ejection causes stasis of blood inside the LV that can result in catastrophic 
intracardiac thrombus formation. Rarely, thrombus may form at the aortic root and ascending aorta when the aortic valve does not open. ${ }^{23}$ Systemic thromboembolism may occur when the aortic valve opens again later in the recovery phase of the heart. A higher anticoagulation intensity and target activated clotting time or activated partial thromboplastin time should be considered in patients with very poor LV contractility.

\section{Acute pulmonary oedema}

The configuration of peripheral VA-ECMO, unlike cardiopulmonary bypass, does not provide 100\% bypass of the cardiopulmonary circulation. Some venous blood may still flow through the right ventricle and pulmonary circulation and finally into the LV. The left heart also receives blood through collaterals of the bronchial and pulmonary arterial circulations. In the presence of severe LV failure, the LV fails to eject blood and the aortic valve fails to open due to retrograde pressure from the peripheral VA-ECMO. Distension of LV occurs followed by hydrostatic pulmonary oedema. Daily echocardiographic assessment is necessary to assess spontaneous echo contrast or thrombus inside the LV chamber. An inotrope (eg adrenaline) can be used to increase LV contractility and promote the emptying of blood. Vasodilators, when used in a delicate balance with inotropes, can help to decrease the afterload and facilitate aortic valve opening. Percutaneous drainage of the left atrium or surgical drainage of the LV has to be considered in refractory cases. $^{24-26}$

\section{Differential hypoxia}

Patients who have concomitant respiratory and cardiac failure, who are on peripheral VA-ECMO with the return cannula inside the femoral artery, are at risk of developing differential hypoxia. Patients with poor respiratory function eject poorly oxygenated blood antegrade from the LV into the ascending aorta where it mixes with the fully oxygenated blood flowing retrograde from the ECMO circuit. During the recovery phase of the heart, more poorly oxygenated blood is pumped from the LV while the retrograde flow from ECMO, which carries fully oxygenated blood, is relatively weaker. At this state, the upper body including the brain is perfused by poorly oxygenated blood while the lower part of the body is supplied by fully oxygenated blood. As the left and right coronary arteries originate from the root of the aorta, the myocardium is susceptible to hypoxia. ${ }^{27}$ Therefore, it is important to monitor the oxygen saturation in both hands for patients receiving peripheral VA-ECMO. If differential hypoxia occurs, ventilator settings are increased to maximise lung oxygenation. In severe cases, the VA-ECMO circuit may be converted into a venoarterial-venous (VAV) configuration with an additional return cannula placed in the right internal jugular vein. Oxygenated blood will then be ejected from the LV to supply the upper part of the body. ${ }^{28}$

\section{Complications specific to cannulation}

\section{Vascular injury}

Vessel wall injury can be catastrophic with massive blood loss. To minimise this risk, cannulation should be carried out by trained personnel under ultrasound or fluoroscopic guidance. The cannula introducer should be retracted once the cannula tip is inside the vessel before further cannula advancement.

\section{Limb ischaemia}

Limb ischaemia is commonly seen in peripheral VA-ECMO when the return cannula is placed in the femoral artery. Peripheral vascular disease, young age, and large-calibre cannula are underlying risk factors. ${ }^{29,30}$ If the cannulation procedure is difficult requiring multiple attempts at vessel puncture, any haematoma formation with its mass effect will compromise downstream perfusion of the leg. The leg may then develop ischaemia, compartment syndrome, or rhabdomyolysis if a reperfusion cannula is not placed in a timely manner. ${ }^{31}$

\section{Role of echocardiography in extracorporeal membrane oxygenation}

Echocardiography is essential during the course of VA-ECMO support. It helps select suitable patients, assist in safe cannulation, monitor response to ECMO support, detect complications, and assess recovery for weaning from ECMO. ${ }^{32}$

\section{Selection of suitable patients}

Patients who require VA-ECMO support usually have severe heart failure. Echocardiography can be used to exclude contra-indications to VA-ECMO such as cardiac tamponade, unrepaired aortic dissection, and severe aortic regurgitation.

\section{Assist safe cannulation}

Echocardiography also helps assess structural heart abnormalities that may hinder correct positioning of the cannula. The presence of Chiari network in the right atrium, and prominent interatrial septal aneurysm are well-known congenital defects that impede proper cannula position. This is particularly important in the setting of VA-ECMO when a second return cannula is placed inside the right internal jugular vein to form a VAV configuration. Ideally the tip of the access cannula, if placed inside 
the IVC, should be just proximal to the entry into the right atrium, whereas the tip of the return cannula should be at the mid-right atrium (Fig 4a). Transoesophageal echocardiography is especially useful to guide correct placement of the ECMO return cannula in the superior vena cava, whereas transthoracic echocardiography is useful to locate the position of the access cannula that is placed inside the inferior vena cava.

\section{Monitoring response to extracorporeal membrane oxygenation support}

Daily echocardiographic examination is necessary to assess aortic valve opening, LV chamber size, and ventricular contractility. Patients on peripheral VA-ECMO have a lower LV preload and higher LV afterload. The LV may become enlarged when the aortic valve does not open due to increased afterload. Stasis of blood inside the LV increases the risk of thrombus formation (Fig $4 \mathrm{~b}$ ). Inotropes may be used to increase myocardial contractility while vasodilators may be used to decrease afterload, both facilitating the opening of the aortic valve.

\section{Detection of complications}

Transoesophageal echocardiography is particularly useful to locate intracardiac thrombi. Thrombus can be present inside the LV chamber, inside the superior vena cava, above the aortic valve, or between the balloon of the IABP and the tip of the return cannula inside the descending aorta. Migration of the thrombus can cause pulmonary embolism or acute cerebral embolic infarction.

\section{Weaning of extracorporeal membrane oxygenation}

There are no specific echocardiographic protocols for ECMO weaning. A trial-off ECMO can be considered, however, when the left ventricular ejection fraction (LVEF) is $>40 \%$, left ventricular outflow tract velocity time integral (LVOT VTI) is $>10 \mathrm{~cm}$, and there is no LV dilatation or cardiac tamponade. During the weaning trial, ECMO flow is usually reduced by $0.5 \mathrm{~L} / \mathrm{min}$ every $30-60$ minutes while vital signs (blood pressure, pulse pressure, pulse rate) and echocardiographic parameters

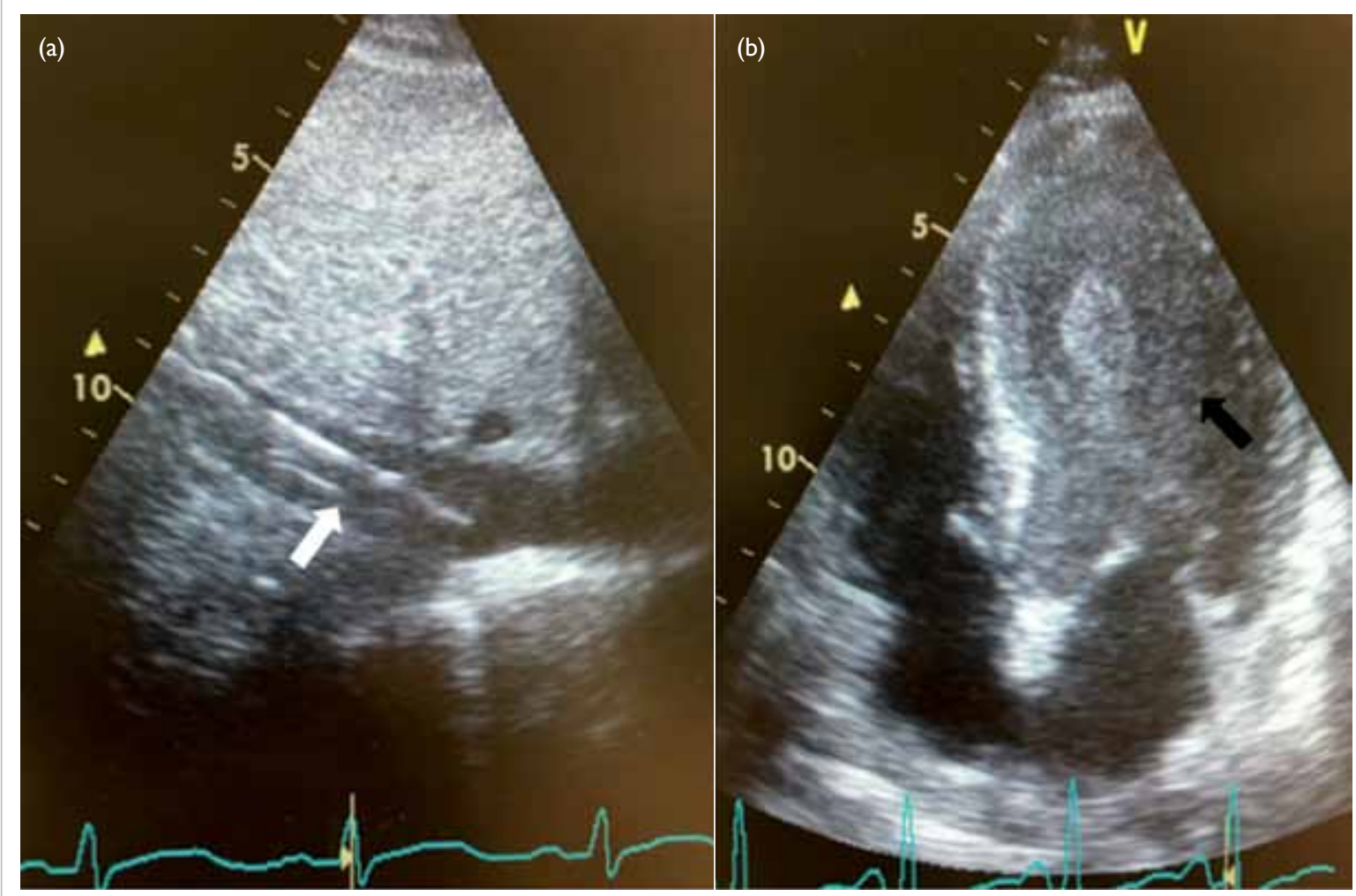

FIG 4. Use of echocardiography in venoarterial extracorporeal membrane oxygenation (VA-ECMO)

(a) Position of the access cannula inside the inferior vena cava (arrow) - the subcostal view of transthoracic echocardiography is often used to locate the position of the access cannula. Ideally the tip of the access cannula should be just beyond the junction of the right atrium and inferior vena cava

(b) Presence of thrombus inside the left ventricle (arrow) - this patient has a non-ST-segment elevation myocardial infarction and developed refractory cardiogenic shock during percutaneous coronary intervention (PCI). Peripheral VA-ECMO is set up to provide haemodynamic support. Day I after PCl, the left ventricular ejection fraction was approximately I0\%. Spontaneous echo contrast and thrombus were seen inside the left ventricle 
(LVEF, LV dimension, aortic valve opening, LVOT VTI) are closely monitored. Patients who are able to wean off VA-ECMO retain stable blood pressure, satisfactory contractility, and LVOT VTI during the weaning process. ${ }^{33}$

\section{Weaning from venoarterial extracorporeal membrane oxygenation}

The timing of weaning from VA-ECMO is important as premature withdrawal will expose the heart to the stress effects of high-dose inotropes, whereas unnecessary extension of VA-ECMO can increase the risks of ECMO-related complications. Different ECMO centres may have different weaning guidelines. In general, patients who are ready to be weaned from VA-ECMO have signs of native heart recovery that include improving aortic pulsatility (pulse pressure), improving myocardial contraction on echocardiography, reduction of ECMO blood flow with the same pump driving force, lessening of inotrope dependence, less demand for renal replacement therapy, decreasing pulmonary capillary wedge pressure and central venous pressure, and improving right ventricular function. ${ }^{34}$ Weaning from VA-ECMO is commonly done under echocardiographic assessment. An LVEF of $>40 \%$, LVOT VTI of $>10 \mathrm{~cm}$, and normal LV size all suggest a higher chance of successful weaning. ${ }^{35-37}$ Even when the trial-off ECMO is successful, some centres will consider leaving the cannulae temporarily $(<24$ hours) in place in case the patient deteriorates. Continuous infusion of heparinised saline to these cannulae is necessary to avoid thrombus formation.

\section{Conclusion}

Venoarterial ECMO is a proven strategy and is being increasingly used to support patients with cardiovascular collapse, as a bridge to recovery or more definitive therapies. Initiation should be carefully considered with regard to patient selection. Understanding the physiology of and interplay between the artificial circuit and the native heart, together with management strategies for specific patient care, stringent monitoring, and early detection of complications are essential for the success of VA-ECMO.

\section{References}

1. ECLS registry report. International summary. Ann Arbor, MI: The Extracorporeal Life Support Organization; Jul 2016.

2. Zeymer U, Hochadel M, Hauptmann KE, et al. Intra-aortic balloon pump in patients with acute myocardial infarction complicated by cardiogenic shock: results of the ALKKPCI registry. Clin Res Cardiol 2013;102:223-7.

3. Thiele H, Zeymer U, Neumann FJ, et al. Intraaortic balloon support for myocardial infarction with cardiogenic shock. N Engl J Med 2012;367:1287-96.

4. Beckmann A, Benk C, Beyersdorf F, et al. Position article for the use of extracorporeal life support in adult patients. Eur J Cardiothorac Surg 2011;40:676-80.

5. ELSO adult cardiac failure supplement to the ELSO general guidelines. Version 1.3. Ann Arbor, MI: The Extracorporeal Life Support Organization; 2013.

6. Chung M, Shiloh AL, Carlese A. Monitoring of the adult patient on venoarterial extracorporeal membrane oxygenation. Scientific World Journal 2014;2014:393258.

7. Bělohlávek J, Mlček M, Huptych M, et al. Coronary versus carotid blood flow and coronary perfusion pressure in a pig model of prolonged cardiac arrest treated by different modes of venoarterial ECMO and intraaortic balloon counterpulsation. Crit Care 2012;16:R50.

8. Brehm C, Schubert S, Carney E, et al. Left anterior descending coronary artery blood flow and left ventricular unloading during extracorporeal membrane oxygenation support in a swine model of acute cardiogenic shock. Artif Organs 2015;39:171-6.

9. Ostadal P, Mlcek M, Kruger A, et al. Increasing venoarterial extracorporeal membrane oxygenation flow negatively affects left ventricular performance in a porcine model of cardiogenic shock. J Transl Med 2015;13:266.

10. Chauhan S, Subin S. Extracorporeal membrane oxygenation, an anesthesiologist's perspective: physiology and principles. Part 1. Ann Card Anaesth 2011;14:218-29.

11. Gattinoni L, Carlesso E, Langer T. Clinical review: Extracorporeal membrane oxygenation. Crit Care 2011;15:243.

12. Petroni T, Harrois A, Amour J, et al. Intra-aortic balloon pump effects on macrocirculation and microcirculation in cardiogenic shock patients supported by venoarterial extracorporeal membrane oxygenation. Crit Care Med 2014;42:2075-82.

13. Romeo F, Acconcia MC, Sergi D, et al. Percutaneous assist devices in acute myocardial infarction with cardiogenic shock: Review, meta-analysis. World J Cardiol 2016;8:98111.

14. Lin LY, Liao CW, Wang CH, et al. Effects of additional intraaortic balloon counter-pulsation therapy to cardiogenic shock patients supported by extra-corporeal membranous oxygenation. Sci Rep 2016;6:23838.

15. Madershahian N, Nagib R, Wippermann J, Strauch J, Wahlers T. A simple technique of distal limb perfusion during prolonged femoro-femoral cannulation. J Card Surg 2006;21:168-9.

16. Kimura N, Kawahito K, Ito S, et al. Perfusion through the dorsalis pedis artery for acute limb ischemia secondary to an occlusive arterial cannula during percutaneous cardiopulmonary support. J Artif Organs 2005;8:206-9.

17. Spurlock DJ, Toomasian JM, Romano MA, Cooley E, Bartlett RH, Haft JW. A simple technique to prevent limb ischemia during veno-arterial ECMO using the femoral artery: the posterior tibial approach. Perfusion 2012;27:141-5.

18. Lorusso R, Barili F, Mauro MD, et al. In-hospital neurologic complications in adult patients undergoing venoarterial extracorporeal membrane oxygenation: results from the Extracorporeal Life Support Organization Registry. Crit Care Med 2016;44:e964-72.

19. Mateen FJ, Muralidharan R, Shinohara RT, Parisi JE, 
Schears GJ, Wijdicks EF. Neurological injury in adults treated with extracorporeal membrane oxygenation. Arch Neurol 2011;68:1543-9.

20. Kasirajan V, Smedira NG, McCarthy JF, Casselman F, Boparai N, McCarthy PM. Risk factors for intracranial hemorrhage in adults on extracorporeal membrane oxygenation. Eur J Cardiothorac Surg 1999;15:508-14.

21. Toomasian JM, Bartlett RH. Hemolysis and ECMO pumps in the 21st century. Perfusion 2011;26:5-6.

22. Lyu L, Long C, Hei F, et al. Plasma free hemoglobin is a predictor of acute renal failure during adult venousarterial extracorporeal membrane oxygenation support. J Cardiothorac Vasc Anesth 2016;30:891-5.

23. Madershahian N, Weber C, Scherner M, Langebartels G, Slottosch I, Wahlers T. Thrombosis of the aortic root and ascending aorta during extracorporeal membrane oxygenation. Intensive Care Med 2014;40:432-3.

24. Rupprecht L, Flörchinger B, Schopka S, et al. Cardiac decompression on extracorporeal life support: a review and discussion of the literature. ASAIO J 2013;59:547-53.

25. Alkhouli M, Narins CR, Lehoux J, Knight PA, Waits B, Ling FS. Percutaneous decompression of the left ventricle in cardiogenic shock patients on venoarterial extracorporeal membrane oxygenation. J Card Surg 2016;31:177-82.

26. Soleimani B, Pae WE. Management of left ventricular distension during peripheral extracorporeal membrane oxygenation for cardiogenic shock. Perfusion 2012;27:32631.

27. Cove ME. Disrupting differential hypoxia in peripheral veno-arterial extracorporeal membrane oxygenation. Crit Care 2015;19:280.

28. Biscotti M, Lee A, Basner RC, et al. Hybrid configurations via percutaneous access for extracorporeal membrane oxygenation: a single-center experience. ASAIO J 2014;60:635-42.
29. Foley PJ, Morris RJ, Woo EY, et al. Limb ischemia during femoral cannulation for cardiopulmonary support. J Vasc Surg 2010;52:850-3.

30. Bisdas T, Beutel G, Warnecke G, et al. Vascular complications in patients undergoing femoral cannulation for extracorporeal membrane oxygenation support. Ann Thorac Surg 2011;92:626-31.

31. Roussel A, Al-Attar N, Khaliel F, et al. Arterial vascular complications in peripheral extracorporeal membrane oxygenation support: a review of techniques and outcomes. Future Cardiol 2013;9:489-95.

32. Douflé G, Roscoe A, Billia F, Fan E. Echocardiography for adult patients supported with extracorporeal membrane oxygenation. Crit Care 2015;19:326.

33. Aissaoui N, Guerot E, Combes A, et al. Two-dimensional strain rate and Doppler tissue myocardial velocities: analysis by echocardiography of hemodynamic and functional changes of the failed left ventricle during different degrees of extracorporeal life support. J Am Soc Echocardiogr 2012;25:632-40.

34. Pappalardo F, Pieri M, Arnaez Corada B, et al. Timing and strategy for weaning from venoarterial ECMO are complex issues. J Cardiothorac Vasc Anesth 2015;29:906-11.

35. Platts DG, Sedgwick JF, Burstow DJ, Mullany DV, Fraser JF. The role of echocardiography in the management of patients supported by extracorporeal membrane oxygenation. J Am Soc Echocardiogr 2012;25:131-41.

36. Scherer M, Sirat AS, Moritz A, Martens S. Extracorporeal membrane oxygenation as perioperative right ventricular support in patients with biventricular failure undergoing left ventricular assist device implantation. Eur J Cardiothorac Surg 2011;39:939-44.

37. Santelices LC, Wang Y, Severyn D, et al. Development of a hybrid decision support model for optimal ventricular assist device weaning. Ann Thorac Surg 2010;90:713-20. 